5. Daudén E, Castañeda S \& Suárez C et al (2013), "Clinical practice guideline for an integrated approach to comorbidity in patients with psoriasis", J Eur Acad Dermatol Venereol, 27, 1387-1404.

6. Evaluation Expert Panel on Detection, and Treatment of High Blood Cholesterol in Adults (Adult Treatment Panel III) (2002), "Third Report of the National Cholesterol Education Program (NCEP) Expert Panel on Detection, Evaluation, and
Treatment of High Blood Cholesterol in Adults (Adult Treatment Panel III) final report", Circulation, 106(3143-3421

7. Garshick MK \& Kimball AB (2015), " Psoriasis and the life cycle of persistent life effects", Dermatol Clin; 3, 25-39.

8. Grozdev I, Korman N \& Tsankov N (2014), "Psoriasis as a systemic disease", Clinics in Dermatology, 32, 343-350.

\title{
ĐÁNH GIÁ KẾT QUẢ CHUYỂN THẦN KINH XI CHO THẦN KINH TRÊN VAI TRONG ĐIỀU TRI LIÊTT ĐÁM RỐI CÁNH TAY Ở NGƯỜII LỚN
}

\author{
Đào Văn Giang*, Trần Thị Thanh Huyền*, Nguyễn Hồng Hà*
}

\section{TÓM TẮT}

Mục tiêu: Phẫu thuật chuyển thần kinh XI cho thần kinh trên vai để phục hồi chức năng của vai. Đối tượng và phương pháp: Nghiên cứu được thực hiện trên 62 bệnh nhân bị liệt ĐRTKCT được chuyển thần kinh XI cho thần kinh trền vai tai Bênh viên Viêt Đức trong thời gian từ 1/2016 đến 12/2020. Phương pháp nghiên cứu hồi cứu, mô tả cắt ngang. Kết quả: 62 bệnh nhân trong đó tỉ lệ nam/nữ: 61/1, tuổi từ 1856 tưổi, trung bình $27,5 \pm 7,9$ tuổi. Nguyên nhân chủ yễu do tại nạn giao thông $(90,3 \%)$. Thời điểm phẫu thuật chủ yếu là trước 6 tháng. Kết quả phục hồi dạng vai rất tốt ở 6,67\% các trường hợp, phục hồi dạng vai $30-120$ độ đạt $86,67 \%$. Phục hồi xoay ngoài của vai đạt $51,12 \%$. Kết luận: Việc chuyển thần kinh XI cho thần kinh trên vai nhằm phục hồi động tác dang vai và xoay ngoàilà một lựa chọn hữu ích và có giá trị trong điều trị liệt đám rối thần kinh cánh tay

Từ khóa: Liệt đám rối thần kinh cánh tay, thần kinh XI, trên vai

\section{SUMMARY}

ACCESSORY NERVE TRANSFER TO SUPRASCAPULARIS NERVE FOR RECONSTRUCTION OF SHOULDER FUNCTION

Purpose: Accessory nerve transfer to suprascapularis nerve for reconstruction of shoulder fuction. Material and method: 62 patients with traumatic brachial plexus injuries underwent surgical reconstruction with accessory to suprascapular nerve transfers. Method study is retrospective, cross-section study. Results: 62 patients, ratio male/female: 61/1, range of age from 18 to 56 years old. Average of age is $27,5+/-7,9$ years. The waiting time before surgery 6 monthsis the most common. Abduction shoulder recovery $>120$ degree was $6,67 \%$, from $30-120$ was $86,67 \%$. Recovered active external rotation of over 30 degree was $51,12 \%$. Conclusion: In brachial plexus

*Bênh viên Hữu nghi Việt Đức

Chịu trách nhiệm chính: Đào Văn Giang

Email: dr.dzang@gmail.com

Ngày nhận bài: $27 / 6 / 2021$

Ngày phản biên khoa học: $2 / 8 / 2021$

Ngày duyệt bài: $22 / 8 / 2021$ injury, using the spinal accessory nerve for transfer to the suprascapular nerve is reliable and provides some recovery of abduction for a large majority of patients.

Keywords: Spinal accessory nerve; brachial plexus; nerve transfer; nerve grafting; suprascapular nerve.

\section{I. ĐĂTT VẤN ĐỀ}

Tổn thương đám rối thần kinh cánh tay (ĐRCT) do chấn thương khá thường gặp, gây ra tình trạng tổn thương chức năng nghiêm trọng và hay gặp ở người trong độ tuổi lao động. Việc điều trị chấn thương đám rối thần kinh cánh tay cần phối hợp của nhiều kĩ thuật từ giai đoạn can thiệp về phẩu thuật thần kinh, giai đoạn chuyển gân, chuyển cơ, đóng cứng các khớp [4]. Phẫu thuật tái tạo lại chức năng của vai là ưu tiên hàng đầu ở những bệnh nhân tổn thương toàn bộ đám rối thần kinh cánh tay. Cách tiếp cận phổ biến nhất để tái tạo lại chức năng của vai là chuyển thần kinh XI (thần kinh phụ) cho thần kinh trên vai. Trên thế giới - nhìn lại y văn và lịch sử về chuyển thần kinh điều trị tổn thương ĐRCT được phát triển từ năm 1994, tác giả Oberlin và cộng sự lần đầu tiên đề xuất phương pháp chuyển một phần TK trụ cho TK cơ nhị đầu để làm gấp khuỷu (Oberlin I). Năm 2003, Leechavengvongs và cs thực hiện chuyển nhánh TK đầu dài cơ tam đầu cho nhánh trước TK mũ, đồng thời chuyển TK XI cho TK trên vai để phuc hồi dạng và xoay ngoài khớp vai. [6]. Tại Việt Nam, 2005 tác giả Võ Văn Châu đã thực hiện chuyển thần kinh XI cho thần kinh cơ bì qua đoạn ghép thần kinh hiển cho 57 bệnh nhân [1]. Nguyễn Việt Tiến [2], tác giả thực hiện phẫu thuật chuyển ghép TK từ rễ C7 bên đối diện cho TK cơ bì và TK giữa qua đoạn ghép là TK trụ gập đôi, có nối mạch nuôi để điều trị tổn thương hoàn toàn $Đ R C T, \ldots$

Tại Bệnh viện Việt Đức, trong những năm gần đây đã ứng dụng kỹ̃ thuật vi phẫu trong điều trị liệt đám rối thần kinh cánh tay. Trong đó có 
phẫu thuật chuyển thần kinh XI cho thần kinh trên vai được thực hiện thường quinhằm phục hồi động tác dạng vai và xoay vai. Tuy nhiên, vẫn chưa báo cáo nào tổng kết đánh giá về kĩ thuật này. Để có một góc nhìn sâu sắc và khẳng định hơn trong điều trị liệt ĐRCT chúng tôi thực hiện nghiên cứu: "Đánh giá kết quả chuyển thần kinh XI cho thần kinh trên vai trong điêu trị liệt đám rối thần kinh cánh tay người lớn" với mục tiêu: Đánh giá kêtt quả chuyển thần kinh XI cho thần kinh trên vai ở bệnh nhân liệt đám rối thần kinh người lớn từ năm 2016-2020.

\section{II. ĐỐI TƯỢNG VÀ PHƯƠNG PHÁP NGHIÊN CỨU}

2.1. Đối tượng nghiên cứu. Đối tượng nghiên cứu là 62 bệnh nhân bị tổn thương nhổ hoăcc đút rễ TK từ C5- T1 của ĐRCT do chấn thương được phẫu thuâat, trong đó có thực hiện kĩ thuật chuyển thần kinh từ thần kinh XI cho thần kinh trên vai nhằm phục hồi động tác dạng vai và xoay ngoài vai tại Bệnh viện Hữu nghị Việt Đức trong thời gian từ 01/2016 đến 12/2020

2.2. Phương pháp nghiên cứu: Phương pháp nghiên cứu hồi cứu, mô tả cắt ngang.

\section{KẾT QUẢ NGHIÊN CỨU VÀ BÀN LUÂN}

3.1 Đặc điểm đối tượng nghiên cứu. Chúng tôi thực hiện nghiên cứu trên 62 bệnh nhân bị liệt đám rối thần kinh cánh tay, trong đó có tỉ lệ phân bố giới tính $\mathrm{Nam} / \mathrm{Nữ}=61 / 1$. Tuổi từ 18- 56 tuổi, trung bình là: $27,5 \pm 7,9$ tuổi

Nguyên nhân: Chủ yễu do tai nạn giao thông chiếm $56 / 62$ bệnh nhân $(90,3 \%$ ), chỉ có $3 / 62$ bệnh nhân $(4,9 \%)$ tai nạn lao động, 2/62 bệnh nhân $(3,2 \%)$ bị tai nạn bạo lực và $1 / 62$ bệnh nhân $(1,6 \%)$ tai nạn sinh hoạt.

Vekris $M$, nghiền cứu trền $67 \mathrm{BN}$ có độ tuổi trung bình là 24,6 tuổi, trong đó phần lớn là $B N$ nam (chiếm trên $90 \%$ ), nguyên nhân do tai nạn giao thông chiếm 90\% [7]. Trong một nghiên cứu trên $520 \mathrm{BN}$ bị tổn thương ĐRCT tác giả Songcharoen P.[6], trong đó 93,5\% nam, nguyên nhân do tai nan giao thông chiếm $82 \%$ và độ tuổi trung bình là 23 tuổi. Nghiên cứu của chúng tôi cũng có nhiều điểm tương tự như với các tác giả khác.

Thời điểm phẫu thuât: chúng tôi phân làm hai nhóm, nhóm phẫu thuật tại thời điểm trước 6 tháng sau tai nạn và nhóm phẫu thuật tại thời điểm sau khi bị tai nạn 6 tháng sau tai nạn, trong đó thời điểm phẫu thuât trung bình của chúng tôi là 4,3 tháng. Một trong những yếu tố làm ảnh hưởng đến kết quả chuyển thần kinh là tuổi của bệnh nhân, ở BN cao tuổi thì phục hồi kém hơn BN trẻ tuổi. Bênh nhân được mổ sớm thời điểm trước 6 tháng thì khả năng phục hồi tốt hơn nhóm đối tượng còn lại, nếu thời điểm phẫu thuật trên 12 tháng kể từ khi bị chấn thương thì nguy cơ không phục hồi hay phục hồi rất kém. Ray. W.Z [8]cho rằng tốt nhất nên phẫu thuât ở thời điểm từ 3 đến 6 tháng sau khi chấn thương và muộn nhất là 12 tháng. Trong nghiên cứu này của chúng tôi, đa số các bênh nhân được tiến hành phẫu thuật tương đối sớm chiếm 83,9\%.

$16,1 \%$

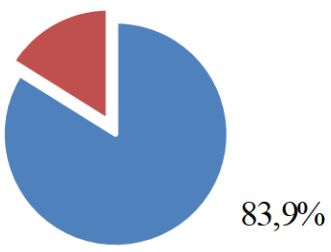

- Từ lúc chấn thương đến 6 tháng

- Trên 6 tháng

Biểu đồ 3.1. Thời điểm được phẫu thuật (tính từ lúc tai nạn)

\subsection{Kết quả sau phẫu thuât}

Bảng 3.1. Phục hối biên độ dạng vai sau phẫu thuật

\begin{tabular}{|c|c|c|c|c|c|c|}
\hline \multirow{3}{*}{$\begin{array}{c}\text { Mức dạng } \\
\text { vai }\end{array}$} & \multicolumn{6}{|c|}{ Sau phâu thuật } \\
\hline & \multicolumn{2}{|c|}{3 tháng $(n=62-4=58)$} & \multicolumn{2}{|c|}{6 tháng $(n=62-11=51)$} & \multicolumn{2}{|c|}{12 tháng $(n=45)$} \\
\hline & $\mathbf{n}$ & $\%$ & $\mathbf{n}$ & $\%$ & $\mathbf{n}$ & $\%$ \\
\hline <30 độ & 35 & 60,34 & 11 & 21,56 & 6 & 13,33 \\
\hline $30-60^{0}$ & 23 & 39,66 & 36 & 72,5 & 22 & 48,89 \\
\hline $61-90^{0}$ & 0 & 0 & 4 & 7,84 & 14 & 31,11 \\
\hline $90-120^{0}$ & 0 & 0 & 0 & 0 & 3 & 6,67 \\
\hline
\end{tabular}

Chúng tôi nhận thấy việc chuyển thần kinh từ XI cho thần kinh trên vai đã kích hoạt và tao dẫn truyền nhanh chóng, dễ dàng trong việc tập luyện các động tác vì tương đối sinh lí (nâng vai thành dạng vai), thể hiện ở đánh giá vào thời điểm 3 tháng sau mổ, có 39,66\% bệnh nhân có biểu hiện phục hồi dạng vai >30 độ. Các bệnh nhân không chỉ hồi phục lại về dạng vai mà còn điều chỉnh lại bán trật khớp vai nhờ sự tái sinh thần kinh của cơ trên gai.

Khi tác giả Jayme bắt đầu chuyển thần kinh XI cho thần kinh trên vai, với thất bại được xác 
định là dạng vai ít hơn 30 độ thì tỉ lệ thất bại chiếm $10 \%$ [3]. Tác giả khuyến nghị lấy ngưỡng dạng vai 30 độ để đánh giá thành công hay thất bại vì với mức dạng vai của biên độ này, ngưỡng sai khớp vai đã được điều chỉnh và bệnh nhân có thể vận động khớp vai. Chúng tôi nhận thấy trong nghiên cứu có những bệnh nhân không phục hồi dạng vai hơn 30 độ. Điều này có thể giải thích do tổn thương hai chố của thần kinh trên vai, tuy nhiên tỉ lệ này thấpMột lý do khác là tất cả bệnh nhân đều có cơ chế kéo căng khi bị chấn thương đám rối thần kinh cánh tay và có những tổn thương trên vi thể về cấu trúc sợi trục của cả nơi cho và nơi nhận thần kinh và chính điều này có thể làm kết quả hồi phục của một số bệnh nhân ở mức kém.

Kết quả chuyển dây TK XI cho trên vai trong các nghiên cứu có sự khác nhau. Trong một nghiên cứu bao gồm 21 bệnh nhân, Malessy và cộng sự đã quan sát thấy sự phục hồi của cơ trên gai và dưới gai ở $85 \%$ và $75 \%$ bệnh nhân, tương ứng thông qua kiểm tra điện chẩn cơ. Tuy nhiên, hoạt động giạng và xoay ngoài vai với sự co cơ $\geq 3$ tương ứng chỉ thấy ở $24 \%$ và $14 \%$ bệnh nhân. Ngược lại, Tersis và Cs đã quan sát thấy kết quả từ tốt đến xuất sắc của động tác dạng vai và xoay ngoài ở $79 \%$ và $55 \%$ bệnh nhân tương ứng. Kết quả tốt nhất đạt được khi phẫu thuật trong vòng 6 tháng sau chấn thương và không sử dụng đoạn ghép. Như vậy nếu so sánh thì kết quả của chúng tôi khi đánh giá động tác dạng vai thì gần với kết quả của Malessy hơon Tersis, còn khi đánh giá động tác xoay ngoài thì gần với nghiên cứu của Tersis và cộng sự hơn.

Bảng 3.2. Phục hồi biên độ xoay ngoài của khớp vai

\begin{tabular}{|c|c|c|c|c|c|c|}
\hline \multirow{3}{*}{$\begin{array}{c}\text { Mức xoay } \\
\text { ngoài }\end{array}$} & \multicolumn{6}{|c|}{ Sau phâu thuật } \\
\hline & \multicolumn{2}{|c|}{3 tháng $(n=62-4=58)$} & \multicolumn{2}{|c|}{6 tháng $(n=62-11=51)$} & \multicolumn{2}{|c|}{12 tháng $(n=45)$} \\
\hline & $\mathbf{n}$ & $\%$ & $\mathbf{n}$ & $\%$ & $\mathbf{n}$ & $\%$ \\
\hline$<30^{\circ}$ & 49 & 84,42 & 28 & 54,9 & 22 & 48,88 \\
\hline $30^{\circ}-<90^{\circ}$ & 9 & 15,51 & 23 & 45,1 & 18 & 40,00 \\
\hline $90^{\circ}-<120^{\circ}$ & 0 & 0 & 0 & 0 & 4 & 11,11 \\
\hline$>120$ & 0 & 0 & 0 & 0 & 1 & 2,22 \\
\hline
\end{tabular}

Đánh giá về phục hồi động tác xoay ngoài, sau 12 tháng, tỉ lệ phục hồi động tác xoay ngoài $>30$ độ chiếm tới $51,12 \%$. Chúng tôi cũng chưa có giải thích rõ ràng về sự phục hồi của động tác xoay ngoài. Không dùng các mảnh ghép thần kinh khi chuyển thần kinh và cần lưu ý chọn lọc đầu xa của thần kinh XI khoẻ tại vị trí gần với cơ nhất có thể làm tăng khả năng hồi phục của động tác xoay ngoài. Nghiên cứu đánh giá về chuyển thần kinh XI cho thần kinh trên vai ở bệnh nhân liệt toàn bộ đám rối thần kinh cánh tay của Jayme A.B. [3] cũng cho kết quả gân như vậy, ông cũng đưa ra giả thuyết về khả năng hồi phục kém của động tác xoay ngoài ở bệnh nhân liệt toàn bộ là (1) số lượng sợi trục myelin của thần kinh XI là không đủ tương thích với thần kinh trên vai (1300 và 3800$)$ nên phục hồi ở cơ trên gai nhiều hơn cơ dưới gai, (2) Cơ đối kháng - cơ dưới vai có vai trò trong sự ổn định của đầu xương cánh tay có thể bị tổn thương.

\section{KẾT LUÂ̂N}

Việc chuyển thần kinh $X I$ cho trên vai nhằm phục hồi động tác dạng vai và xoay ngoàilà một lựa chọn hữu ích và có giá trị trong điều trị liệt đám rối thần kinh cánh tay. Phẫu thuật này thực hiện đớn giản và tỉ lệ hồi phục cao. Việc được tiển hành phẫu thuật sớm sau khi có chẩn đoán xác định tổn thương đám rối thần kinh cánh tay giúp tăng khả năng hồi phục. Vì vâyy việc thăm khám, chẩn đoán và thực hiện phấu thuật sớm sau tổn thương là cần thiết và hết sức quan trọng.

\section{TÀI LIÊU THAM KHẢO}

1. Võ Văn Châu (2005), "Chuyển ghép thân kinh XI và thần kinh cơ bì để phục hồi gập khuỷu trong liệt đám rối thần kinh cánh tay", Thời sự Y dược học, 10(4) tr. 195-202.

2. Nguyên Việt Tiến, Nguyễn Viết Ngooc, Lê Văn Đoàn và cs (2011), "Kết quảchuyênrể thần kinh C7 từ bên lành trong điều trị nhổ các rễ thân kinh đám rối cánh tay", Tạp chí $Y$ dược học lâm sàng 108,6 , tr. 299-306.

3. Jayme A.B, et al (2016): "Results of spinal accessory to suprascapular nerve transfer in 110 patients with complete palsy of the brachial plexus" J Neurosurg Spine; Jun 24(6):990-5

4. Malessy MJA, de Ruiter GCW, de Boer KS, Thomeer RTWM (2004): "Evaluation of suprascapular nerve neurotization af- ter nerve graft or transfer in the treatment of brachial plexus traction lesions". J Neurosurg 101:377-389,

5. Ray W.Z., Chang J., Hawasli A., et al. (2016), "Motor Nerve Transfers: A Comprehensive Review", Journal of Neurosurgery, 78(1), pp. 1-26.

6. Songcharoen P., (1995), "Brachial plexus injury in Thailand: A report of 520 cases", Microsurgery, 16(1), pp. 35-39.

7. Vekris M.D., Beris A.E., Johnson E.O., et al, (2006), "Musculocutaneous neurotization to restore elbow flexion in brachial plexus paralysis", Microsurgery, 26(4), pp. 325-329. 